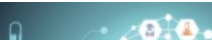 \\ Chemical Education \\ xerarioment A CHIMIA Column \\ Topics for Teaching: Chemistry in Nature
}

\section{Geckos, Ceilings and van der Waals $\$$}

\section{Catherine E. Housecroft ${ }^{\star}$}

${ }^{*}$ Correspondence: Prof. C. E. Housecroft, Department of Chemistry, University of Basel, BPR 1096, Mattenstrasse 24a, CH-4058 Basel

E-mail: catherine.housecroft@unibas.ch

\section{Abstract: The ability of a gecko to run rapidly across ceilings} and up and down vertical walls is a striking example of the application of van der Waals interactions.

Keywords: Chemical education - Gecko · Hierarchical structures · van der Waals interactions

In the Mediterranean region, Turkish geckos (Hemidactylus turcicus, Fig. 1) are a common sight after dark and show a remarkable ability to run rapidly up and down walls and across ceilings, defying gravity despite their mass. An adult Turkish gecko weighs around 50-70 g and can run at a speed of $1 \mathrm{~m} \mathrm{~s}^{-1}$. Evolution has equipped geckos with toe-pads with hierarchical structures leading to strong frictional and adhesive forces which can be switched on and off allowing step intervals of around 20 $\mathrm{ms}$. The toe-pad structures are described as hierarchical because they progress from macro- to micro- to nanoscales. The detailed structure is revealed using scanning electron microscopy (SEM). ${ }^{1]}$ Each toe possesses around 20 ridges (lamellae) which are 1-2 mm long (Fig. 2). Hairs (or setae) protrude from each lamella, and together, the five toes on each foot possess hundreds of thousands of hairs, each 30-130 $\mu \mathrm{m}$ long and 5-10 $\mu \mathrm{m}$ wide ( $c a$. one-tenth the diameter of a human hair). Each hair (seta) terminates in a branched structure which is composed of hundreds of structural features called spatulae. Each is about $0.5 \mu \mathrm{m}$ long and $0.1-0.2$ $\mu \mathrm{m}$ wide and it is these structures that make contact with the surfaces over which the gecko runs. ${ }^{[2]}$ The hierarchical structures may be appreciated by following the increasing magnification of the scanning electron micrographs on going from Fig. 2 (scale bars are $300 \mu \mathrm{m}$ and $100 \mu \mathrm{m}$ ) to Fig. 3 (scale bars are $10 \mu \mathrm{m}$ and $1 \mu \mathrm{m})$. The magnification in Fig. $3 \mathrm{~b}$ demonstrates the submicron dimensions of the spatulae.

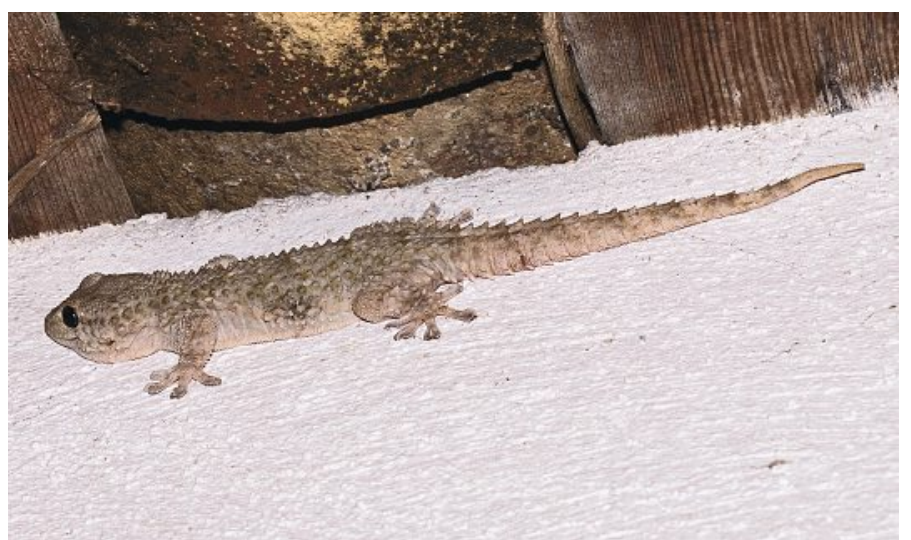

Fig. 1. Turkish gecko (Hemidactylus turcicus). @ Edwin C. Constable 2018.
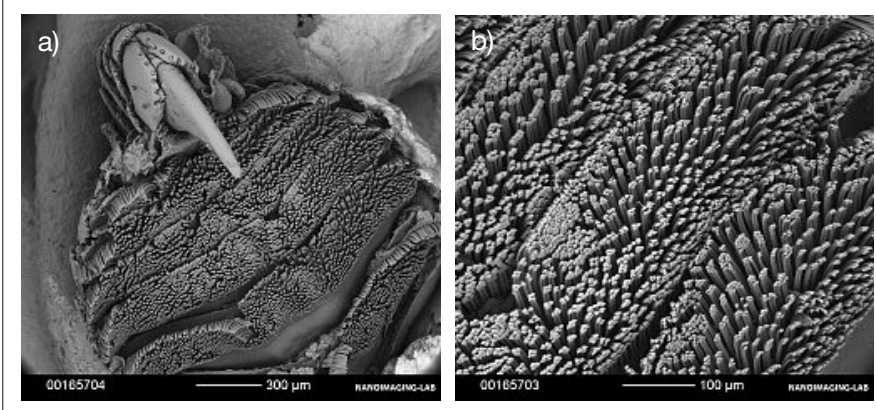

Fig. 2. Scanning electron micrographs of the underside of the foot of a gecko at different magnifications showing (a) several lamellae with setae, and (b) closer detail of the setae (hairs). (c) Evi Bieler, Nano Imaging Lab, University of Basel.

While the hair of mammals is made from the fibrous protein $\alpha$-keratin, the setae of a gecko are composed of $\beta$-keratin. $\alpha$ and $\beta$-keratins differ in their secondary structure. The sequence of amino acids in a protein defines its primary structure, and the presence of $\alpha$-helices, $\beta$-sheets, turn and coils defines the secondary structure. The proteins that make up the setae are only slightly elastic and possess long, axially oriented filaments. ${ }^{3]}$ Gecko $\beta$-keratin is rich in the amino acids glycine, proline and serine (Scheme 1), and the protein is in the $16.8-18.0 \mathrm{kDa}$ range. ${ }^{[4]}$ Cysteine residues present in $\beta$-keratin can undergo oxidative coupling to form disulfide bridges that cross-link protein chains (Scheme 1), thereby increasing the strength of the keratinous hairs. ${ }^{[5]}$
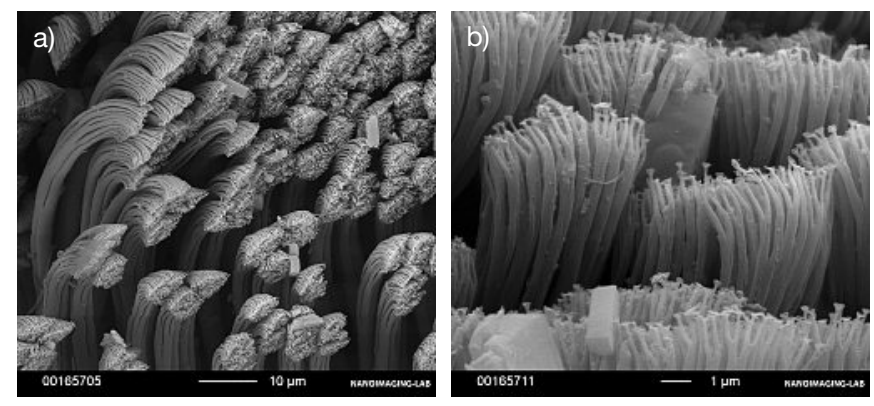

Fig. 3. Scanning electron micrographs at different magnifications showing (a) branching of the setae and (b) the spatulae on the toe-pad of a gecko. (c) Evi Bieler, Nano Imaging Lab, University of Basel.

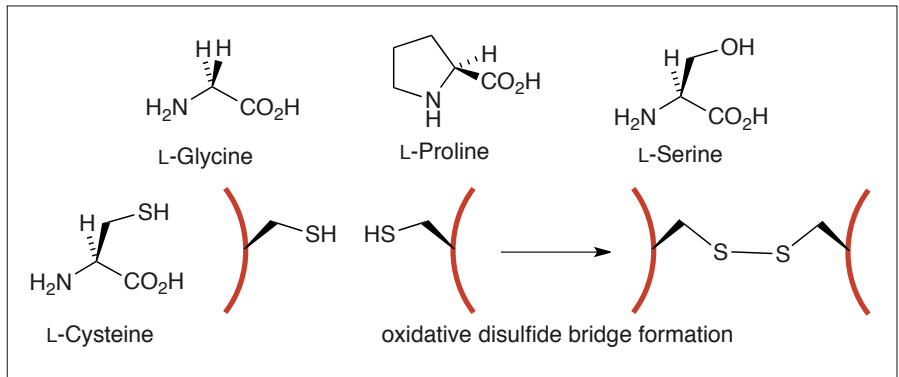

Scheme 1. Structures of L-glycine, L-proline, L-serine and L-cysteine, and representation of disulfide-cross linking of protein chains. 
Two possible adhesion mechanisms to explain how geckos stay firmly in place involve van der Waals interactions (attractive or repulsive forces) and thin-film capillary forces. By measuring the force of a gecko toe on hydrophobic GaAs versus hydrophilic $\mathrm{SiO}_{2}$ surfaces, Autumn et al. observed that adhesion to both hydrophilic and hydrophobic polarizable surfaces were similar. Since wet, capillary adhesion (involving capillary condensation of atmospheric water) precludes a gecko from sticking to a hydrophobic surface, these experiments demonstrated the critical role of van der Waals interactions between the branched hairs on the feet of a gecko and a surface. ${ }^{[6,7]}$ Significantly, however,

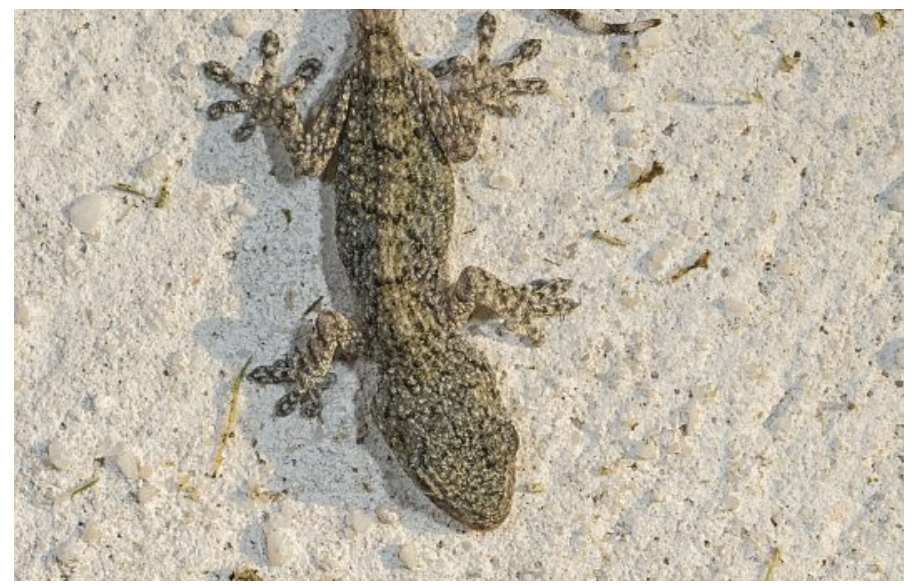

Fig. 4. A young Turkish gecko. @ Edwin C. Constable 2018. geckos are adapted to adhere to surfaces in both dry (Fig. 4) and humid conditions. ${ }^{[8]}$ Changes in the orientations of the setae with respect to the surface increase and decrease the adhesion forces, allowing geckos to rapidly move their feet over surfaces. Nature's answer to geckos staying attached to ceilings as they run now motivates research into artificial surfaces with strong adhesive properties.

\section{Acknowledgements}

I thank Evi Bieler and Dr Markus Dürrenberger in the Nano Imaging Lab, University of Basel, for providing the SEM images.

[1] H. Gao, X. Wang, H. Yao, S. Gorb, E. Arzt, Mech. Mater. 2005, 37, 275.

[2] B. Bhushan, Langmuir 2012, 28, 1698.

[3] M. Toni, L. D. Valle, L. Alibardi, J. Proteome Res. 2007, 6, 1792.

[4] L. D. Valle, A. Nardi, V. Toffolo, C. Niero, M. Toni, L. Alibardi, Dev. Dynam. 2007, 236, 374.

[5] K. S. Endoh, T. Kawakatsu, F. Müller-Plathe, J. Phys. Chem. B 2018, 122 , 2203.

[6] K. Autumn, Y. A. Liang, S. T. Hsieh, W. Zesch, W. P. Chan, T. W. Kenny, R. Fearing, R. J. Full, Nature 2000, 405, 681.

[7] K. Autumn, M. Sitti, Y. A. Liang, A. M. Peattie, W. R. Hansen, S. Sponberg, T. W. Kenny, R. Fearing, J. N. Israelachvili, R. J. Full, Proc. Nat. Acad. Sci. 2002, 99, 12252

[8] N. S. Pesika, H. Zeng, K. Kristiansen, B. Zhao, Y. Tian, K. Autumn, J. Israelachvili, J. Phys.: Condens. Matter 2009, 21, 4664132.

${ }^{\S}$ This column is one of a series designed to attract teachers to topics that link chemistry to Nature and stimulate students by seeing real-life applications of the subject. 